\title{
Project Teaching for the Course of Digital Electronic Technology Experiment
}

\author{
Desheng Liu ${ }^{1}$, Chunjiang $\mathrm{Li}^{2 \mathrm{a}, \star}$, Siqing Tian${ }^{1}$, Xiaojun $\mathrm{Ma}^{3}$, Jiamei Xue ${ }^{1}$ \\ ${ }^{1}$ School of Information and electronic technology, Jiamusi University, Jiamusi, 154007, China; \\ 2 Dean's office, Jiamusi University, Jiamusi, 154007, China; \\ ${ }^{3}$ School of Mechanical Engineering Jiamusi University, Jiamusi, 154007, China. \\ ajmslcj@sohu.com
}

Keywords: Digital Electronic Technology, Experiment, Project Teaching Method.

\begin{abstract}
Digital electronic technology is an engineering professional course, a solid foundation for learning, improve the students' practical ability. According to the digital electronic technology experimental teaching reform and exploration of the existing problems, project driven teaching method was proposed in digital electronic technology training, the idea of project teaching and implementation method. Through the combination of software simulation and hardware experiment, we study the curriculum reform from three aspects: teaching methods, teaching methods and laboratory management.
\end{abstract}

\section{Introduction}

Digital electronic technology course is one of the core courses in electrical engineering and automation specialty, is an important bridge, contact the public basic courses and professional courses at the same time, the course is a closely related to engineering design and analysis of practical devices, the course is electrical engineering students contact the actual project first threshold [1].

In recent years, the national robot design contest, electronic design contest and other competitions are increasing, more highlights the importance of digital electronic technology and other basic courses. The experiment course of digital electronic technology is the bridge between theory and practice, which makes students have the ability to analyze and design the digital circuit through the experiment teaching. The ability of practice and innovation is one of the training objectives of engineering specialty.

The traditional experimental teaching, including teaching contents, teaching methods, and teaching methods cannot meet the students' desire to explore knowledge, classroom learning atmosphere, students' learning interest is not high, poor ability of self-study problems emerge in an endless stream. Therefore, it is necessary to reform the experiment course of digital electronic technology in order to stimulate students' interest in learning and improve teaching quality. Yang Chunling introduction of foreign schools teaching case, practice teaching process, through the design and verification of a comprehensive project to improve the students' interest in learning [2], literature [3] introduction of case teaching method in the classroom teaching of digital electronic technology, digital electronic technology in line with the characteristics of this discipline, cultivate students' Innovation consciousness, improve the students the ability of engineering practice, and ultimately achieve the purpose of cultivating applied talents. The research of Jiang Chunyan on Vocational Education of curriculum project, the project teaching method is applied to the digital electronic technology course, put forward the teaching of professional basic course project, the teaching quality and student's ability to improve.

In this paper, the teaching methods, teaching methods and experimental teaching management are discussed in three directions, combined with practical application, from the start of the project teaching model. 


\section{Teaching Methods Research}

How to stimulate students' enthusiasm for learning? First of all, we should arouse the interest of the students, so as to achieve the challenging task, to achieve the joy of success, and to improve self-confidence. Project teaching method can achieve the above purpose.

The general idea: "interest driven, independent experiments, focusing on the process to implement the principle of" constructing "the basic theory, practice theory to strengthen the practice" teaching mode, centered on project goals, follow the "project to introduce a project on a project implementation project review and summary of experimental teaching the main learning courses around the specific project design, strong operability, the task of teaching activities, students complete the project tasks through activities, to learn and master the relevant knowledge and skills to [5-7].

\subsection{Project Design}

First of all, the selection of the project is the key of the project teaching method. Content not only to cover the knowledge points of the syllabus, but also must have a challenge, to create space for students.

In the experiment of digital electronic technology, the design and application of combinational logic circuit, decoder, encoder, trigger, shift register, counter, 555 timer, LED digital display, etc.. The content is designed to several projects, the project also includes a number of tasks. This is independent of the knowledge together, and the use of learning problem solving mode to teach students reflects the project teaching method in "learning by doing" and "doing", "learning by doing" features.

Table 1. Main project tasks and quality development

\begin{tabular}{|c|c|c|}
\hline Project Name & Task & Quality Development \\
\hline $\begin{array}{l}\text { Acousto optic } \\
\text { control circuit }\end{array}$ & $\begin{array}{l}\text { Identification of digital integrated circuits } \\
\text { - Functional test of common TTL gate and } \\
\text { cmos gate circuit } \\
\text { Fabrication and debugging of acousto } \\
\text { optic control circuit }\end{array}$ & $\begin{array}{l}\text { Several gates are designed to realize their } \\
\text { functions }\end{array}$ \\
\hline Majority voting & $\begin{array}{l}\text { The application of basic gate circuit to the } \\
\text { design of voting circuit } \\
\text { To legislative door circuit fabrication and } \\
\text { debugging }\end{array}$ & $\begin{array}{l}\text { Several gates are designed to realize their } \\
\text { functions }\end{array}$ \\
\hline $\begin{array}{l}\text { The production of } \\
\text { digital display }\end{array}$ & $\begin{array}{l}\text { Test and application of the function of the } \\
\text { common scale integrated circuit } \\
\text { Design of combinational logic circuits } \\
\text { using integrated circuits; } \\
\text { The manufacture and debugging of digital } \\
\text { display }\end{array}$ & Design display two bit digital circuit; \\
\hline $\begin{array}{l}\text { Eight way } \\
\text { responder }\end{array}$ & $\begin{array}{l}\text { The function test and application of } \\
\text { trigger; } \\
\text { Identification, function and test method of } \\
\text { integrated trigger } \\
\text { The design and production of intelligent } \\
\text { race responder }\end{array}$ & $\begin{array}{l}\text { The display circuit in combination, } \\
\text { responder number display }\end{array}$ \\
\hline $\begin{array}{l}\text { Digital clock } \\
\text { design }\end{array}$ & $\begin{array}{l}\text { The functions of the commonly used } \\
\text { integrated and decimal counter products } \\
\text { Identification and testing; } \\
\text { The application of integrated counter and } \\
\text { arbitrary hexadecimal counter; } \\
\text { Using a } 555 \text { timer to form an oscillator } \\
\text { The oscillator counter display is combined } \\
\text { together to form a clock circuit and debug }\end{array}$ & $\begin{array}{l}\text { The development of calibration, alarm } \\
\text { clock, stopwatch, countdown and other } \\
\text { functions }\end{array}$ \\
\hline
\end{tabular}

\subsection{Project Implementation}

The spirit of the students as the main body, the teacher as the leading principle, each class divided into several groups, each group of students according to the requirements of the project, the key to solve the problem clearly, collect related knowledge involved in the project; group members a clear 
division of labor, solidarity and cooperation, to jointly develop the project work plan and work flow rules and determine the project; the required components of the circuit by circuit simulation; experiment; each group of students to complete the circuit fabrication, inspection, debugging and fault elimination.

During the implementation of the project, the teacher will give full attention and necessary help. After the completion of the project, students are required to demonstrate and explain the project. Teachers from the process, the results, the ability to innovate three aspects of evaluation.

\section{Teaching Devices Research}

\subsection{Application of Circuit Simulation Software EDA}

In the process of project implementation, fully combined with the existing hardware experiment system by using the simulation software, the first software simulation in the design of each functional module, the hardware circuit simulation with further experimental requirements,

This eliminates the cumbersome installation and debugging of electronic components; will not damage the device, saves the expenditure; shorten the design cycle; in addition, the simulation effect is clear and intuitive, to facilitate students' understanding of knowledge and memory, software simulation by experiment place, students can also practice in residential homes.

Electronic design automation technology (Electronic Design Automatior EDA) with the rapid development of integrated circuits and computer technology came into being a kind of advanced, fast and effective electronic design automation tools.

The introduction of EDA into the course of digital electronic technology can improve the quality of teaching, teaching efficiency and enrich teaching content. Figure 1 is designed with 74LS112D asynchronous addition counter.

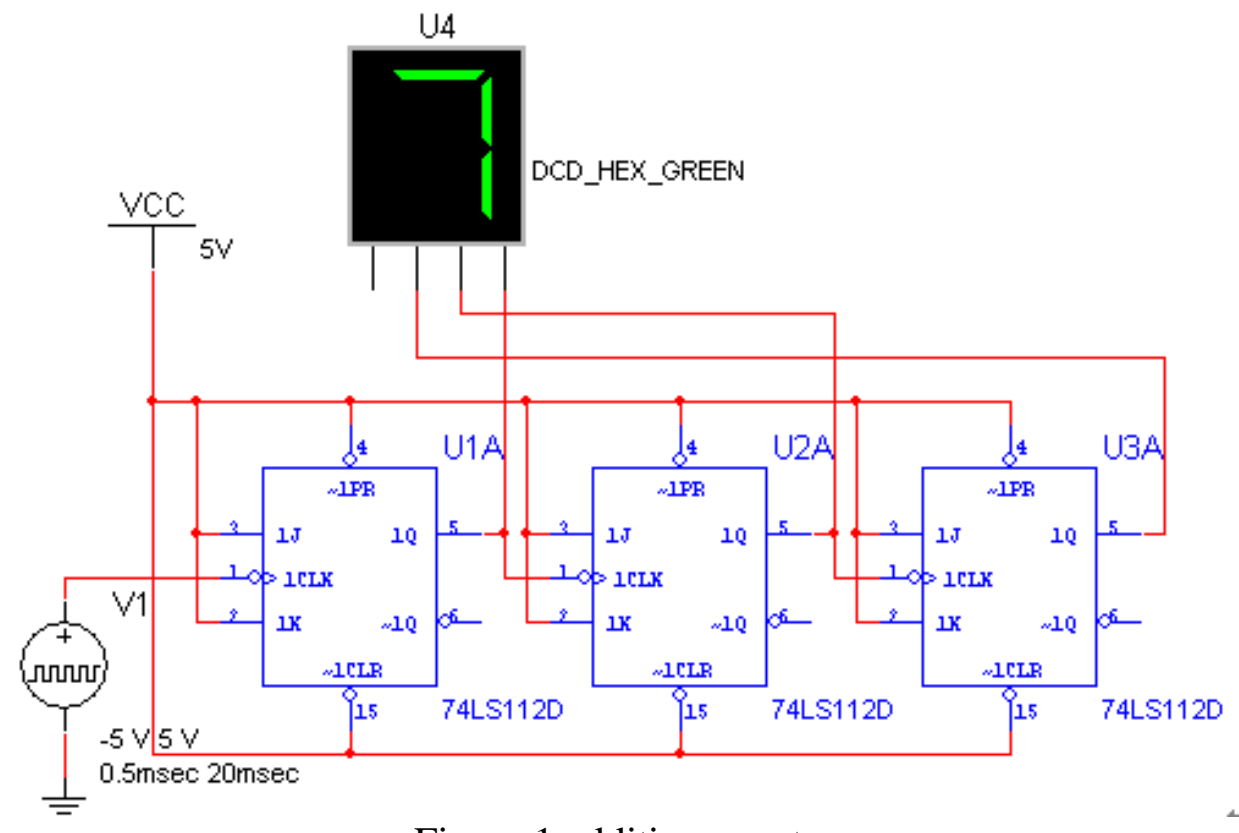

Figure 1 addition counter

\section{2 make full use of Internet resources}

The experimental requirements are relatively high, less hours of experimental projects, students can not be limited to the time to complete the experiment or can not fully grasp the experiment, resulting in poor experimental results. The number of electrical experiments can be based on the campus network, the realization of three-dimensional teaching environment, the basic knowledge of experimental teaching, the key points, experimental materials, video and other related data are uploaded to the site, to maximize meet the teaching needs of [4]. 


\section{4. laboratory management}

In the past experiment teaching, the laboratory can only be used in class. Compared with the teaching resources, the students have some limitations. Therefore, we should make full use of the laboratory and create a learning environment for the students. Therefore, to extend the laboratory time, over the weekend to open for students to use, while the development of laboratory management system, students should consciously abide by and tested in strict accordance with the implementation of the project steps, to reduce the waste of chips.

\section{Conclusion}

In this era of information explosion, the students get information from different ways, the traditional teaching has been unable to fully three-dimensional show good teaching results. Reflect the project teaching method is the process of students' independent learning and practice of the project teaching method, change the past "teacher talk, students listen" teaching mode, students become the subject of learning, teachers have become a guide. Under the guidance of teachers, students participate in the initiative, unity and cooperation, not only to improve the students' theoretical knowledge and practical skills, but also cultivate their comprehensive ability to solve practical problems. Meet the training objectives of colleges and universities.

\section{Acknowledgments}

This work was supported in part by Jiamusi University education and teaching research (No. JYZL2015-05 and No.2016JC1007) and Heilongjiang higher education reform project (No. JG2014011046).

\section{References}

[1]. Wang Meiling, Wang Jun, Jiang Zemin, et al. Exploration and exploration of digital technology based on PSoC [J]. laboratory, 2014,08:162-165,

[2]. Yang Chunling, Zhu Min, Zhang Yan. Exploration and practice of research teaching methods of digital electronic technology [J]. China University of education, 2014, 02:58-60.

Application of case teaching in the course of digital electronic technology

[3]. Zhang Zhang Wei, Zhang Ge [J]. China Electric Power Education, 2011, 18:173-174.

[4]. Jiang Chunyan. Research and practice of project teaching method in digital electronic technology [J]. China Electric Power Education, 2010, 35:51-52.

[5]. Lining, Luo Qinjuan, Qian Hua, Fan Guiling. Experiment teaching practice and analysis of [J]. Experimental technology and management of independent design of digital electronic technology, 2015, 06:161-163+167.

[6]. Wan Yi. Research on the practice teaching evaluation system and evaluation method of digital electronic technology [J]. Experimental science and technology, 2013, 05:122-124+143.

[7]. Yang Xue, Wang Mei. CDIO in the teaching reform of digital electronic technology applications [J]. Journal of Nanjing Institute of Technology (SOCIAL SCIENCE EDITION), 2010, 01:65-68. 